\title{
Analysis of cellular responses to free radicals: focus on exercise and skeletal muscle
}

\author{
Scott K. Powers* and Shannon L. Lennon \\ Departments of Exercise and Sport Sciences and Physiology, Center for Exercise Science, University of Florida, Gainesville, \\ Florida 32611, USA
}

\begin{abstract}
Muscular exercise results in an increased production of radicals and other forms of reactive oxygen species (ROS). Recent evidence suggests that radicals and other ROS are an underlying aetiology in exercise-induced disturbances in muscle redox status. These exercise-induced redox disturbances in skeletal muscle are postulated to contribute to both muscle fatigue and/or exerciseinduced muscle injury. To defend against ROS, muscle cells contain complex cellular defence mechanisms to reduce the risk of oxidative injury. Two major classes (enzymic and non-enzymic) of endogenous protective mechanisms work together to reduce the harmful effects of oxidants in the cell. Primary antioxidant enzymes include superoxide dismutase (EC 1.15.1.1; SOD), GSH peroxidase (EC 1.11.1.9; GPX), and catalase (EC 1.11.1.6); these enzymes are responsible for removing superoxide radicals, $\mathrm{H}_{2} \mathrm{O}_{2}$ and organic hydroperoxides, and $\mathrm{H}_{2} \mathrm{O}_{2}$ respectively. Important non-enzymic antioxidants include vitamins $\mathrm{E}$ and $\mathrm{C}, \beta$-carotene, $\mathrm{GSH}$ and ubiquinones. Vitamin E, $\beta$-carotene and ubiquinone are located in lipid regions of the cell, whereas GSH and vitamin $\mathrm{C}$ are in aqueous compartments of the cell. Regular endurance training promotes an increase in both total SOD and GPX activity in actively-recruited skeletal muscles. High-intensity exercise training has been shown to be generally superior to low-intensity exercise in the upregulation of muscle SOD and GPX activities. Also, training-induced upregulation of antioxidant enzymes is limited to highly-oxidative skeletal muscles. The effects of endurance training on non-enzymic antioxidants remain a relatively uninvestigated area.
\end{abstract}

Oxidative stress: Exercise: Skeletal muscle: Free radicals: Reactive oxygen species

Regular muscular exercise is associated with many positive health benefits, including the reduced risk of coronary artery disease. Nonetheless, it is now clear that muscular activity results in an increased production of radicals and other forms of reactive oxygen species (ROS; Davies et al. 1982; Jackson et al. 1985; Reid et al. 1992a,b; Borzone et al. 1994; O'Neil et al. 1996). This increase is significant because growing evidence indicates that ROS are an underlying aetiology in exercise-induced disturbances in muscle homeostasis (e.g. redox status) which are associated with muscle fatigue (Novelli et al. 1990; Shindoh et al. 1990; Barclay \& Hansel, 1991; Nashawati et al. 1993; Reid et al. 1994), and may also contribute to the late phase of exerciseinduced muscle injury (for review, see Jackson, 1998). Given this potential role of ROS in contributing to a disturbance in muscle homeostasis, it seems logical that skeletal muscle myocytes would contain defence mechanisms to minimize oxidative damage. Indeed, two major classes of endogenous protective mechanisms (i.e. enzymic and nonenzymic antioxidants) work as a unit to reduce the harmful effects of ROS in cells. The purpose of the present review is to provide a brief overview of the effects of regular muscular exercise on skeletal muscle antioxidant systems. Other aspects of this topic have been covered in several recent comprehensive reviews (Ji, 1995a,b; Powers et al. 1999; Powers \& Sen, 1999).

\section{Cellular antioxidant defences}

Both enzymic and non-enzymic antioxidants exist in the intracellular and extracellular environments to detoxify ROS; these antioxidants work as a complex team to remove various types of ROS. To maximize intracellular protection, these scavengers are located throughout the cell and provide protection against ROS toxicity using different approaches. Primary strategies include conversion of ROS 
into less-active molecules (i.e. scavenging), and prevention of the transformation of less-reactive ROS into more damaging forms (i.e. prevention of the transformation of $\mathrm{H}_{2} \mathrm{O}_{2}$ to the damaging hydroxyl radical).

\section{Primary antioxidant enzymes}

Primary antioxidant enzymes in cells include superoxide dismutase (EC 1.15.1.1; SOD), GSH peroxidase (EC 1.11.1.9; GPX) and catalase (EC 1.11.1.6; CAT). Each of these antioxidant enzymes performs a reduction of a particular ROS. Table 1 summarizes the cellular location and antioxidant function of each of these enzymes

Superoxide dismutase. Cellular defence against superoxide radicals is provided by SOD. SOD dismutates superoxide radicals to form $\mathrm{H}_{2} \mathrm{O}_{2}$ and $\mathrm{O}_{2}$. Two isozymes of SOD exist in mammalian skeletal muscle. These isoforms differ in both cellular location and the metal cofactor bound to its active site. The $\mathrm{Cu}-\mathrm{ZnSOD}$ isoform is located primarily in the cytosol, whereas the MnSOD isoform is found in the mitochondria (Grisham \& McCord, 1986; Ohno et al. 1994; Ji, 1995a). According to Ohno et al. (1994) both enzymes catalyse the dismutation of superoxide anions with similar efficiency.

Variation exists in the distribution of the SOD isoforms across tissues; for example, in skeletal muscle $65-85 \%$ total SOD activity exists in the cytosol, whereas 15-35\% total SOD activity is in the mitochondria (Ji et al. 1992). Also, it should be noted that SOD activity is greatest in muscles with a high oxidative capacity (i.e. high percentage of type I (slow) fibres) compared with muscles with low oxidative capacity (i.e. high percentage of type IIb (fast) fibres; Criswell et al. 1993; Powers et al. 1994a).

GSH peroxidase. GPX is an enzyme responsible for reducing $\mathrm{H}_{2} \mathrm{O}_{2}$ or organic hydroperoxides to water and alcohol respectively. This enzyme uses GSH as the electron donor and requires Se as a cofactor (Halliwell \& Gutteridge, 1989). GPX is highly specific for its electron donor (GSH), but this enzyme has a low specificity for substrates; i.e. GPX will reduce a wide range of hydroperoxides, from $\mathrm{H}_{2} \mathrm{O}_{2}$ to complex organic hydroperoxides (Halliwell \& Gutteridge, 1989). This characteristic makes GPX an important cellular protectant against ROS-mediated damage to membrane lipids and other molecules sensitive to oxidation.

Similar to SOD, GPX activity varies across muscle fibre types, with type I (slow) fibres containing the highest activity and type IIb (fast) fibres possessing the lowest activity (Ji et al. 1988; Powers et al. 1994a). GPX is located in both the cytosol and the mitochondria. In skeletal muscle with mixed fibre types approximately $45 \%$ of the GPX activity is found in the cytosol, with the remaining $55 \%$ located in the mitochondria (Ji et al. 1988). This fact allows
GPX to remove $\mathrm{H}_{2} \mathrm{O}_{2}$ and hydroperoxides in both the cytosol and the mitochondria (Ji, 1995a).

In order to function, GPX requires the electron donor, GSH. Since GSH is oxidized by GPX to form GSSH, cells require a method of regenerating GSH. Regeneration of GSH is accomplished by the enzyme GSSG reductase (EC 1.6.4.2; GR) which uses NADPH to provide the reducing power. In tissues other than skeletal muscle NADPH is largely produced by glucose-6-phosphate dehydrogenase (EC 1.1.1.49) via the pentose pathway (Halliwell \& Gutteridge, 1989). In contrast, NADPH in skeletal muscle is primarily produced by isocitrate dehydrogenase (EC 1.1.1.42; Lawler et al. 1993).

GR has a cellular distribution which is similar to GPX, and its activity is higher in oxidative muscles compared with muscles with low oxidative capacity. Although GR is not considered to be a primary antioxidant enzyme, it is an essential enzyme for the normal antioxidant function of GPX.

Catalase. As an antioxidant enzyme, CAT catalyses the breakdown of $\mathrm{H}_{2} \mathrm{O}_{2}$ to form water and $\mathrm{O}_{2}$. To maintain catalytic activity, CAT requires $\mathrm{Fe}^{3+}$ as a cofactor (Halliwell \& Gutteridge, 1989).

While there is overlap between the function of CAT and GPX, the two enzymes differ in their affinity for $\mathrm{H}_{2} \mathrm{O}_{2}$ as a substrate. Mammalian GPX has a much greater affinity for $\mathrm{H}_{2} \mathrm{O}_{2}$ at low concentrations compared with CAT. Thus, when cellular levels of $\mathrm{H}_{2} \mathrm{O}_{2}$ are low GPX is more active than CAT in removing $\mathrm{H}_{2} \mathrm{O}_{2}$ from the cell.

Although CAT is widely distributed in the cell, high concentrations are found in both peroxisomes and mitochondria (Halliwell \& Gutteridge, 1989). Similar to other primary antioxidant enzymes, CAT activity is greatest in muscle fibres with high oxidative capacities and lowest in muscle fibres with low oxidative capacities (Powers et al. 1994a).

\section{Non-enzymic antioxidants}

Many non-enzymic antioxidants exist in cells. Important non-enzymic defences include vitamin $\mathrm{E}$, vitamin $\mathrm{C}$, $\alpha$-lipoic acid (LA), GSH, carotenoids, bilirubin and ubiquinone (Table 2). In the following section we provide a brief overview of each of these non-enzymic antioxidants.

Vitamin E. Vitamin E is an important antioxidant in cell membranes and other lipid components of the cell (Burton \& Ingold, 1989; Janero, 1991; Packer, 1991). The term 'vitamin E' refers to at least eight structural tocopherol or tocotrienol isomers. Of these isomers, $\alpha$-tocopherol is the most investigated and contains the most potent antioxidant activity in biological systems (Burton \& Ingold, 1989; Burton \& Traber, 1990; Janero, 1991; Packer, 1991).

Table 1. Cellular location and antioxidant properties of primary antioxidant enzymes in cells

\begin{tabular}{lll}
\hline Enzymic antioxidants & Cellular locations & Antioxidant properties \\
\hline Mn superoxide dismutase $(E C$ 1.15.1.1) & Mitochondria & Dismutates superoxide radicals \\
Cu-Zn superoxide dismutase & Cytosol & Dismutates superoxide radicals \\
GSH peroxidase $(E C 1.11 .1 .9)$ & Cytosol and mitochondria & Removes $\mathrm{H}_{2} \mathrm{O}_{2}$ and organic hydroperoxides \\
Catalase $(E C$ 1.11.1.6) & Cytosol and mitochondria & Removes $\mathrm{H}_{2} \mathrm{O}_{2}$ \\
\hline
\end{tabular}


Table 2. Cellular location and antioxidant properties of important non-enzymic antioxidants

\begin{tabular}{llc}
\hline Non-enzymic antioxidants & Cellular locations & Antioxidant properties \\
\hline $\begin{array}{l}\text { Vitamin E } \\
\text { Vitamin C (ascorbic acid) }\end{array}$ & $\begin{array}{l}\text { Lipid-soluble phenolic compound; located in membranes } \\
\text { Water-soluble; located in cytosol }\end{array}$ & $\begin{array}{c}\text { Major lipid peroxidation chain-breaking antioxidant } \\
\text { Quenches a wide variety of aqueous-phase ROS; } \\
\text { regenerates vitamin E from its oxidized product }\end{array}$ \\
GSH & $\begin{array}{c}\text { Non-protein thiol in cells; located in both cytosol and } \\
\text { mitochondria } \\
\text { Endogenous thiol; located in both lipid and aqueous }\end{array}$ & $\begin{array}{c}\text { Effective as an antioxidant and in recycling vitamin C; } \\
\text { may also be an effective GSH substitute }\end{array}$ \\
$\begin{array}{l}\text { Ubiquinones } \\
\text { Carotenoids }\end{array}$ & $\begin{array}{l}\text { Lipid-soluble quinone derivatives; located in membranes } \\
\text { Lipid soluble; located primarily in membranes of tissues }\end{array}$ & $\begin{array}{l}\text { Reduced forms are efficient antioxidants } \\
\text { Antioxidant; reduces lipid peroxidation. }\end{array}$
\end{tabular}

ROS, reactive oxygen species.

Vitamin E is a particularly important antioxidant because of its capacity to convert superoxide, hydroxyl and lipid peroxyl radicals to less-reactive forms. Importantly, vitamin E can also break lipid peroxidation chain reactions which occur during ROS-mediated damage to cell membranes (Janero, 1991). However, it should be noted that the interaction of vitamin $\mathrm{E}$ with a radical or other ROS results in a reduction of functional vitamin $\mathrm{E}$ and the creation of a vitamin $\mathrm{E}$ radical. It follows that oxidative stress significantly reduces tissue vitamin $\mathrm{E}$ levels (Burton \& Ingold, 1989; Janero, 1991; Packer, 1991). Nonetheless, the vitamin E radical can be 'regenerated' to its native state by several other antioxidants (Janero, 1991; Packer, 1991). Thus, it is postulated that the ability of vitamin E to serve as an antioxidant is tied to other antioxidants that are capable of recycling vitamin $\mathrm{E}$ during periods of oxidative stress. This point is discussed in more detail in the subsequent sections on vitamin $\mathrm{C}$ and $\mathrm{LA}$.

Vitamin C. Vitamin C (ascorbic acid) is hydrophilic and its antioxidant function is more suited to aqueous environments than vitamin E. At physiological $\mathrm{pH}$ ascorbic acid exists as the ascorbate anion which is widely distributed in mammalian tissues (Yu, 1994).

The antioxidant roles of vitamin $\mathrm{C}$ are numerous. For example, vitamin $\mathrm{C}$ can directly scavenge superoxide, hydroxyl and lipid hydroperoxide radicals. Furthermore, vitamin C plays a key role in recycling vitamin $\mathrm{E}$ (Packer et al. 1979). Nonetheless, while recycling vitamin $\mathrm{E}$, native vitamin $\mathrm{C}$ is converted to a vitamin $\mathrm{C}$ (semidehydroascorbate) radical (Packer et al. 1979). This radical can be reduced back to native vitamin $\mathrm{C}$ by NADH semidehydrascorbate reductase (EC 1.6.5.4), or cellular thiols (e.g. GSH; Packer et al. 1979).

a-Lipoic acid. LA is an endogenous intracellular thiol that acts as a cofactor for $\alpha$-dehydrogenase complexes (Packer, 1994). LA is generally present in limited quantities $(5-25 \mathrm{nmol} / \mathrm{g})$ in animal tissues, and is normally bound to an enzyme complex; LA in this bound form is not active as an antioxidant. Nonetheless, when consumed in the diet, free unbound LA can be an effective antioxidant and can assist in the recycling of vitamin C (Kagan et al. 1992; Packer, 1994). LA can be consumed in the diet and is available as a dietary supplement. When taken in recommended doses as a dietary supplement LA has no known toxic side effects (Packer, 1994). After entering the cell LA is reduced to dihydrolipoic acid, which is a powerful antioxidant against several radical species (Packer, 1994).
GSH. GSH is a tripeptide and is the most abundant nonprotein thiol in mammalian cells (Meister \& Anderson, 1983). Synthesis of GSH occurs primarily in the liver; following synthesis GSH is released into the circulation for transport to peripheral tissues.

Tissue levels of GSH vary widely. For instance, the two highest GSH levels in the body are found in the lens of the eye (10 mM) and the liver (5-7 mM; Ji, 1995a). These high levels of GSH are not surprising considering the fact that these organs are exposed to high levels of ROS and other oxidants. Other key organs such as the lung, kidney, and the heart also contain relatively high levels of GSH (approximately 2-3 mM; Ji, 1995a). Skeletal muscle GSH concentration varies depending on muscle fibre type and animal species; for example, (slow) type I fibres contain $600 \%$ higher GSH content (approximately $3 \mathrm{mM}$ ) compared with (fast) type IIb fibres (0.5 mM; Ji et al. 1992).

GSH has several antioxidant functions. First, GSH readily interacts with a variety of radicals including hydroxyl and carbon radicals, by donating an $\mathrm{H}$ (Yu, 1994). Another important antioxidant function of GSH is to act as a co-substrate with GPX in the elimination of both $\mathrm{H}_{2} \mathrm{O}_{2}$ and other organic peroxides. In this reaction GSH donates a pair of $\mathrm{H}$ and two GSH molecules are oxidized to form GSSG. The regeneration of GSH is achieved by the reduction of GSSG; this reaction is catalysed by GR, with NADPH providing the reducing power (Ji et al. 1992; Ji, 1995a; Vina et al. 1995).

Furthermore, GSH has been shown to be involved in reducing a variety of cellular antioxidants. Indeed, GSH has been reported to reduce vitamin $\mathrm{E}$ ( $\alpha$-tocopheroxyl) radicals that are formed during chain-breaking reactions with alkoxyl or lipid peroxyl radicals (Packer, 1991). Also, GSH is used to reduce the semidehydroascorbate radical (vitamin $\mathrm{C}$ radical) generated during the vitamin $\mathrm{C}$-mediated recycling of vitamin E. Finally, GSH has also been reported to reduce LA to dihydrolipoate. It has been argued that this reaction is important in the recycling of ascorbic acid (Packer, 1994).

Carotenoids. Carotenoids (e.g. $\beta$-carotene) are lipidsoluble antioxidants located in cellular membranes. The antioxidant properties of carotenoids are derived from their chemical structure, which consists of long chains of conjugated double bonds. This structural arrangement permits the scavenging of several ROS (e.g. superoxide radicals and peroxyl radicals; Yu, 1994). In general, most carotenoids exhibit useful biological antioxidant activity, as 
indicated by their ability to reduce the rate of lipid peroxidation induced by radical-generating systems (Krinsky \& Deneke, 1982).

Ubiquinones. Ubiquinones are quinone derivatives that contain an isoprene tail. Ubiquinone homologues containing one to twelve isoprene units occur in nature. Reduced forms of ubiquinones, ubiquinols, are lipid soluble and are efficient antioxidants. Specifically, when compared with ubiquinones, ubiquinols are better antioxidants by several orders of magnitude (Mellors \& Tappel, 1966).

The major form of ubiquinone in human subjects is ubiquinone-10. The concentration of ubiquinone-10 in human plasma varies between 0.4 and $1.0 \mu \mathrm{mol} / \mathrm{l}$; approximately $80 \%$ is present in the reduced state (Aberg et al. 1992). In human tissue ubiquinone-10 is found in relatively high levels in heart, liver, and kidney, $70-100 \%$ of which is in the reduced state (Aberg et al. 1992). In terms of intracellular location, approximately $50 \%$ of the total cellular ubiquinone is located within the mitochondria, $30 \%$ in the nucleus, with the remaining $10 \%$ located in the endoplasmic reticulum and the cytoplasm (Aberg et al. 1992).

The antioxidant properties of ubiquinones were first described by Mellors \& Tappel (1966). Since this early report, numerous papers have concluded that the antioxidant properties of ubiquinones are due to their phenol ring structure (Halliwell \& Gutteridge, 1989). Ubiquinones react with ROS (e.g. oxygen radicals and singlet oxygen) to prevent lipid peroxidation in lipid structures in the cell (Halliwell \& Gutteridge, 1989). Importantly, some ubiquinones may also play a key role in the recycling of vitamin $\mathrm{E}$ during periods of oxidative stress (Kagan et al. 1990).

\section{Exercise training and skeletal muscle antioxidant enzyme activity}

The antioxidant capacity of animal cells is designed to match the rates of radical production. Furthermore, it is well known that the rates of radical production are highly correlated with the cellular levels of $\mathrm{O}_{2}$ consumption. Thus, it is not surprising that tissues with the highest rates of resting $\mathrm{O}_{2}$ consumption (e.g. liver, brain, and kidney) have the greatest antioxidant enzyme activity. Also, skeletal muscles with high oxidative capacities contain greater antioxidant capacities compared with those muscles with lower oxidative potential.

Growing evidence indicates that the antioxidant defence systems of mammalian tissues are capable of adaptation in response to chronic exposure to oxidants. Indeed, it has been shown that exposure of mouse heart to superoxide radicals results in an increased expression of MnSOD (Oberly et al. 1987). Following this logic, since prolonged exercise results in an increased production of oxidants in skeletal muscle, chronic exercise training should upregulate muscle antioxidant enzyme activities. In this regard, there is convincing evidence that endurance exercise training results in an increase in antioxidant enzyme activity in active skeletal muscles. An overview of the major findings regarding the effects of endurance exercise training on the activities of primary antioxidant enzymes in skeletal muscle is presented.

\section{Superoxide dismutase}

While a few studies suggest that endurance training does not elevate SOD activity in skeletal muscles (Alessio \& Goldfarb, 1988; Ji et al. 1988; Laughlin et al. 1990), most studies indicate a training-induced increase in total SOD activity (Jenkins, 1983; Higuchi et al. 1985; Powers et al. 1992; Criswell et al. 1993; Leeuwenburgh et al. 1994, 1997; Powers et al. 1994a,b; Oh-ishi et al. 1997a,b).

A concrete explanation for the lack of agreement among studies is not available. Nonetheless, differences in the techniques used to assay SOD activity, varying types of exercise training programmes, and a difference in fibre composition of the muscles investigated could be important factors. With regard to assay techniques, the relative sensitivity to detect SOD activity varies between assays. Indeed, when comparing seven common assays to estimate SOD activity, Oyanuagui (1984) concluded that a 10-fold difference in sensitivity exists between methods. Hence, investigations using SOD procedures with low sensitivity could fail to observe small-to-moderate training-induced changes in tissue SOD activity due to a limited sensitivity of the assay.

A second possible explanation for the variable SOD findings is the difference in exercise training protocols used by investigators. For example, investigations that have reported training-induced increases in muscle antioxidant enzymes have generally used high-intensity exercise training programmes. This observation implies that intense exercise training programmes are needed to elevate antioxidant enzyme activity in skeletal muscle. To evaluate the effect of exercise intensity and duration on induction of skeletal muscle SOD activity, Powers et al. (1994a) evaluated the relationship between the magnitude of the training stimulus (i.e. exercise intensity and daily duration) and the activity of SOD in locomotor skeletal muscles. The experimental design required groups of rats to run at varying daily durations (i.e. 30, 60, $90 \mathrm{~min} / \mathrm{d}$ ) and different exercise intensities (i.e. 55, 65, $75 \%$ maximum $\mathrm{O}_{2}$ intake). At the completion of 10 weeks of training, locomotor skeletal muscles were removed and assayed to determine SOD activity. The results for the soleus muscle are illustrated in Fig. 1. In short, these data indicate that high-intensity exercise training is superior to low-intensity exercise in the up regulation of skeletal muscle SOD activity.

A cross-sectional analysis of exercise training studies indicates that exercise induction of SOD is fibre-type specific, with highly oxidative muscles being most responsive (Ji et al. 1988; Laughlin et al. 1990; Criswell et al. 1993; Powers et al. 1994a). Fig. 2 illustrates the effects of a 10-week exercise training programme $(60 \mathrm{~min} / \mathrm{d}$ at approximately $75 \%$ maximum $\mathrm{O}_{2}$ intake) on SOD activity in the soleus, red gastrocnemius, and white gastrocnemius muscles obtained from adult rats. It should be noted that training promoted an increase in SOD activity in both the soleus and red gastrocnemius. In contrast, SOD activity in the white gastrocnemius was not altered by training. This finding is notable because the soleus (primarily type I fibres) 


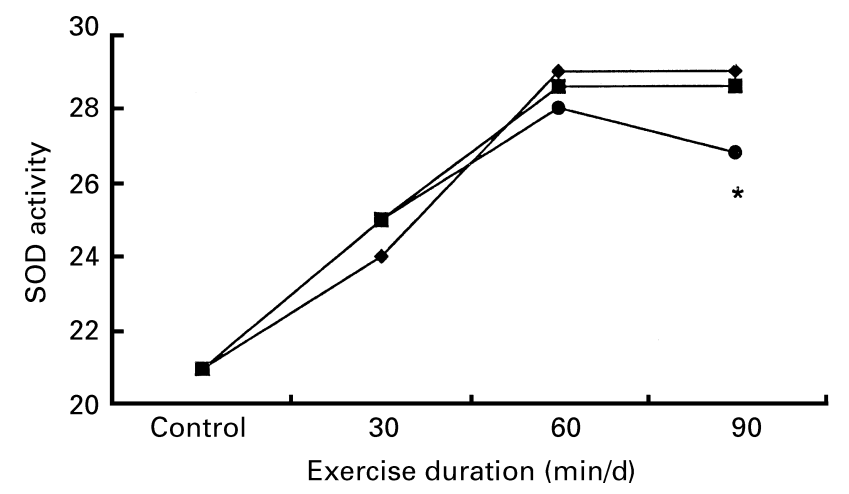

Fig. 1. Effects of the intensity (high, $(\bullet)$; medium, $(\mathbf{\square})$; low, $(\bullet)$ ) and daily duration of exercise training on superoxide dismutase (EC 1.15.1.1; SOD) activity (units/mg protein per $\mathrm{min}$ ) in the rat soleus muscle. It should be noted that skeletal muscle SOD activity increased as a function of both the duration and intensity of exercise training. Mean value was significantly different from those for both medium- and high-intensity-exercise training groups: ${ }^{*} P<0 \cdot 05$. (Data from Powers et al. 1994a.)

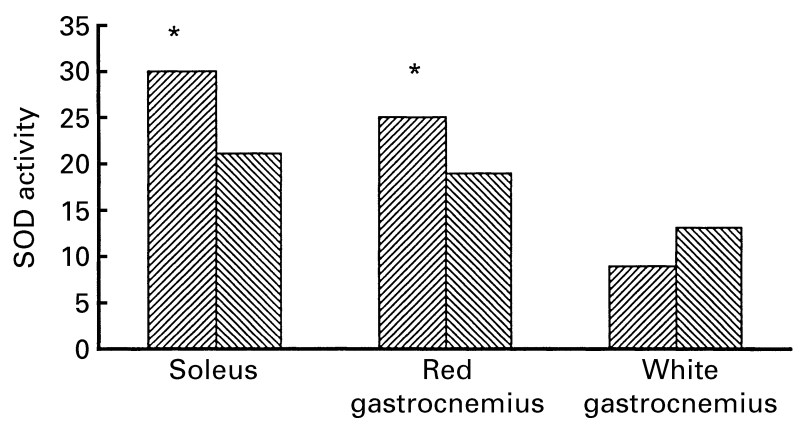

Fig. 2. Effects of skeletal muscle fibre type on exercise-induced increases in superoxide dismutase (EC 1.15.1.1; SOD) activity (units/mg protein per min). Trained, (ma); untrained, (av). It should be noted that exercise training resulted in an up regulation of SOD activity in both the soleus (primarily type I fibres) and red gastrocnemius (type lla fibres) muscles. Also, training did not alter SOD activity with the white gastrocnemius (primarily type llb fibres). Mean values were significantly different from those for the untrained controls: ${ }^{*} P<0.05$. (Data from Powers et al. 1994a.)

and red gastrocnemius (primarily type IIa fibres) contain highly-oxidative fibres, while the white gastrocnemius (primarily type IIb fibres) is composed of highly-glycolytic fibres (Armstrong \& Phelps, 1984).

It seems likely that differences in muscle fibre recruitment patterns may account for these training-induced differences. Nonetheless, the direct influence of exercise intensity and fibre recruitment on the up regulation of SOD activity in individual muscle fibres is difficult to appraise, as the effects of exercise on a muscle fibre is determined by a variety of complex factors (Pette \& Dusterhoft, 1992; Vandenburgh, 1992). Thus, it is unclear as to whether the exercise-induced up regulation of antioxidant enzyme activity in highly-oxidative muscles is due to ordered fibre type recruitment alone or due to fibre type-regulated differences in antioxidant gene expression.

At present, confusion exists regarding which SOD isoforms are up regulated in skeletal muscle following endurance exercise training. For instance, research by both Higuchi et al. (1985) and Vincent et al. (1999) suggests that exercise training results in an increase in the activity of MnSOD with no increase in the $\mathrm{Cu}-\mathrm{Zn}$ isoform of SOD. In contrast, Leeuwenburgh et al. (1997) reported that endurance training promotes an increase in only the $\mathrm{Cu}-\mathrm{Zn}$ isoform of SOD in skeletal muscle. Finally, two contemporary studies have provided new evidence that intense exercise training can result in an up regulation of both $\mathrm{MnSOD}$ and $\mathrm{Cu}-\mathrm{ZnSOD}$ in rat skeletal muscle. For example, studies at the University of Florida (Powers \& Sen, 1999), recently examined the effects of intense endurance training on the activity of SOD isoforms in skeletal muscles of rats. These investigators reported that regular endurance training increases the activity of both MnSOD and $\mathrm{Cu}-\mathrm{ZnSOD}$ in rat oxidative skeletal muscles (i.e. red gastrocnemius). Similar findings have been reported by Oh-ishi et al. $(1997 a, b)$.

Endurance training promotes an increase in the activity of both oxidative enzymes and SOD; however, the increase in oxidative capacity does not appear to be matched by a proportional increase in SOD activity. Indeed, several reports indicate that endurance training does not result in parallel increases in both oxidative and antioxidant enzymes as the training-induced increase in antioxidant enzyme activity is generally lower than the increase in oxidative enzyme activity (Hammeren et al. 1992; Criswell et al. 1993; Powers et al. 1994a). The physiological significance of this oxidative $v$. antioxidant mismatch is unclear and warrants additional experimental attention.

\section{GSH peroxidase}

In general, the literature concerning the effects of endurance training on skeletal muscle GPX activity is consistent, with most studies indicating that regular endurance exercise training results in increased GPX activity in active skeletal muscles (Ji et al. 1988, 1992; Laughlin et al. 1990; Sen et al. 1992; Criswell et al. 1993; Leeuwenburgh et al. 1994, 1997; Powers et al. 1994a,b; Hellsten et al. 1996; Venditti \& Di Meo, 1996, 1997). It appears that exercise training promotes an increase in both cytosolic and mitochondrial GPX activity, with the greater increase occurring in the mitochondria (Ji et al. 1988). This type of adaptation is physiologically important in that GPX would be available to remove hydroperoxides from both the mitochondria and cytosol.

The magnitude of the training-induced increase in muscle GPX activity is influenced by both the intensity and (daily) duration of exercise; for example, when compared with lowto-moderate intensity exercise, high-intensity exercise promotes a greater increase in muscle GPX activity (Criswell et al. 1993; Powers et al. 1994a). Also, longduration exercise training is preferred to short-duration exercise training with respect to the up regulation of GPX activity in skeletal muscles (Powers et al. 1994a,b; Fig. 3).

Similar to SOD, the endurance training-induced up regulation of GPX activity appears to be limited to skeletal muscles with high oxidative capacities (Criswell et al. 1993; Powers et al. 1994a). Furthermore, training does not result in parallel and predictable increases in oxidative enzyme 


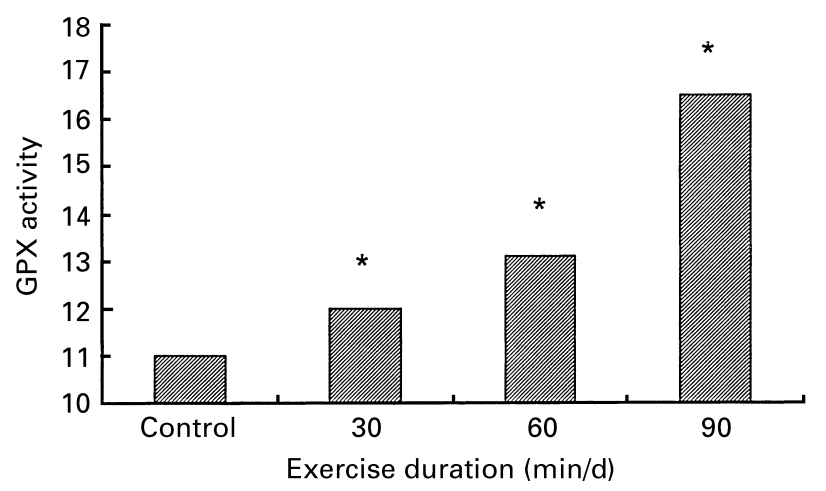

Fig. 3. Effects of exercise duration on the up regulation of GSH peroxidase (EC 1.11.1.9; GPX) activity ( $\mu \mathrm{mol}$ substrate/min per $100 \mathrm{mg}$ protein) in the red gastrocnemius muscle. Mean values were significantly different from that for the control: ${ }^{*} P<0 \cdot 05$. (Data from Powers et al. 1994a.)

activity and GPX activity (Hammeren et al. 1992). As mentioned earlier, the physiological significance of this mismatch between oxidative $v$. antioxidant capacity is worthy of study.

\section{Catalase}

There is little evidence to suggest that exercise training promotes an increase in CAT activity in skeletal muscle (Higuchi et al. 1985; Leeuwenburgh et al. 1994; Powers et al. 1994a,b). In fact, numerous studies have shown that exercise training may result in reduced CAT activity in some locomotor muscles (Alessio \& Goldfarb, 1988; Laughlin et al. 1990; Leeuwenburgh et al. 1997). The explanation for why endurance training may result in lowered CAT activity in muscle remains unclear.

\section{Exercise training and non-enzymic antioxidants}

\section{GSH}

There is growing evidence that regular endurance exercise training promotes an increase in GSH content in oxidative skeletal muscles. Specifically, high-intensity long-duration endurance training has been shown to increase GSH content in the hindlimb muscles of dogs (Sen et al. 1992; Marin et al. 1993) and rats (Leeuwenburgh et al. 1994, 1997). The mechanism to explain this training-induced elevation in muscle GSH is unknown. In theory the increase in GSH content in trained muscles may be explained by increased synthesis and/or the ability of the tissue to take up greater amounts of GSH from the blood. The increased tissue uptake may be due to increased activities of $\gamma$-glutamyltransferase (EC 2.3.2.2), whereas the increase in GSH synthesis may occur due to increases in $\gamma$-glutamylcysteine synthase (EC 6.3.2.2) and GSH synthase (EC 6.3.2.3) (Sen et al. 1992; Marin et al. 1993).

Critical examination of the literature reveals that training adaptation of GSH in muscle is fibre-type specific. The explanation for this muscle fibre-type variation in adaptation could be tied to the rate of GSH utilization $v$. the capacity of GSH uptake within different fibre types. In this regard, activities of the $\gamma$-glutamyl cycle enzymes may play an important role. For instance, endurance training results in significant increases in GSH within the deep vastus laterialis muscle in rats, whereas the GSH levels in the soleus muscle were not elevated in response to training (Leeuwenburgh et al. 1994, 1997). A possible explanation for these findings is that compared with the soleus muscle the deep vastus laterialis muscle has superior $\gamma$-glutamyltransferase activity (Leeuwenburgh et al. 1997). However, no differences existed in $\gamma$-glutamylcysteine synthase activity between these skeletal muscles. This observation implies that the translocation of amino acids across the cell membrane may be the limiting factor in the intracellular assembly of GSH (Ji, 1995a).

While it appears clear that endurance training promotes increased skeletal muscle GSH content, results on the effects of training on GR activity (required to recycle GSSG back to GSH) are less convincing. Whereas some studies indicate that endurance training results in a decrease or no change in GR activity in locomotor muscles (Sen et al. 1992; Leeuwenburgh et al. 1994, 1997), other studies have shown that training promotes an increase in GR activity in skeletal muscle of trained rats (Venditti \& Di Meo, 1997). The explanations for these different findings are unclear.

\section{Vitamin E and other non-enzymic antioxidants}

Studies that examine the effects of endurance training on tissue levels of non-enzymic antioxidants are few. Of the non-enzymic antioxidants, GSH, vitamin E and ubiquinone10 are the only non-enzymic antioxidants that have received significant experimental attention. With regard to vitamin $\mathrm{E}$, several studies have examined the effects of both chronic exercise (i.e. endurance training) and acute exercise on tissue levels of vitamin $\mathrm{E}$ in rodents. Unfortunately, the findings are not consistent. While some investigations have indicated that acute or chronic exercise in young adult rodents is associated with a significant reduction in skeletal muscle vitamin E levels (Gohil et al. 1986; Bowles et al. 1991), other studies have shown no change (Salminen \& Vihko, 1983; Starnes et al. 1989; Tiidus \& Houston, 1993). The explanation for the divergent findings is not clear, and additional experiments are warranted to clarify this issue.

Currently, only one published report exists regarding the effects of acute exercise on vitamin E levels in human skeletal muscle. These investigators reported that a bout of eccentric exercise resulted in a small but significant decrease $(P<0.05)$ in skeletal muscle vitamin E concentrations when expressed per g wet weight (Meydani et al. 1993). Nonetheless, if muscle vitamin E levels were expressed per $\mathrm{mg}$ arachidonic acid, exercise did not alter muscle vitamin E levels.

On a related topic, Packer et al. (1989) have postulated that acute exercise results in an inter-organ transport of vitamin E. Support for this concept can be found in studies indicating that plasma levels of vitamin $\mathrm{E}$ are elevated postexercise (Meydani et al. 1993). This increase could occur due to a release of vitamin $\mathrm{E}$ from adipose tissue, liver and other tissues (Packer et al. 1989). This type of inter-organ transport could be important in maintaining skeletal muscle 
vitamin $\mathrm{E}$ concentrations during acute exercise and/or chronic exercise training.

In summary, more research is required to clarify the effects of acute and chronic exercise training on vitamin $\mathrm{E}$ levels in skeletal muscle. Furthermore, the possibility that exercise results in inter-organ transport of vitamin $\mathrm{E}$ is important and should receive additional research attention.

Studies investigating the effects of endurance exercise training on the ubiquinone content of rat skeletal muscle all indicate that chronic training results in a significant increase $(P<0.05)$ in ubiquinone levels in oxidative muscles (Beyer et al. 1984; Gohil et al. 1987; Karlsson et al. 1996). Furthermore, compared with sedentary controls, the ubiquinone content in human skeletal muscle is higher in physically-active subjects (Karlsson et al 1996). This training-induced increase in skeletal muscle ubiquinone content could be important in protecting membranes from exercise-induced lipid peroxidation.

\section{Summary}

Muscular exercise results in an increased production of radicals and other forms of ROS. Furthermore, growing evidence implicates cytotoxic ROS as an underlying factor in exercise-induced disturbances in muscle redox status; these changes could result in muscle fatigue and contribute to the late phase of exercise-induced muscle injury.

To defend against ROS, muscle cells contain complex cellular defence mechanisms to reduce the risk of oxidative injury. Two major classes of endogenous protective mechanisms work together to reduce the harmful effects of oxidants in the cell: (1) antioxidant enzymes; (2) nonenzymic antioxidants. Key antioxidant enzymes include SOD, GPX and CAT; these enzymes are responsible for removing superoxide radicals, $\mathrm{H}_{2} \mathrm{O}_{2}$ and organic hydroperoxides, and $\mathrm{H}_{2} \mathrm{O}_{2}$ respectively. Important non-enzymic antioxidants include vitamins $\mathrm{E}$ and $\mathrm{C}, \beta$-carotene, $\mathrm{GSH}$ and ubiquinones.

It is generally agreed that regular endurance training promotes an increase in both total SOD and GPX activity in active skeletal muscles. Furthermore, high-intensity exercise training is superior to low-intensity exercise with respect to the up regulation of muscle SOD and GPX activities. Also, training-induced up regulation of antioxidant enzymes is limited to highly-oxidative skeletal muscles. In contrast to the observations indicating that SOD and GPX are up regulated, it appears that training does not result in an increase in muscle CAT activity.

Limited information exists regarding the effects of exercise on non-enzymic antioxidants. Nonetheless, mounting evidence indicates that regular endurance training increases GSH levels in skeletal muscle by elevating GSH concentrations in selected fibres. Although several studies have examined the effects of both chronic exercise training and acute exercise on tissue levels of vitamin $\mathrm{E}$ in rodents, the results are not consistent.

\section{Acknowledgements}

This work was supported, in part, by grants from the American Heart Association-Florida, American Lung
Association-Florida, and the National Institutes of Health (USA).

\section{References}

Aberg F, Appelkvist EL, Dallner G \& Ernster L (1992) Distribution and redox state of ubiquinones in rat and human tissues. Archives of Biochemistry and Biophysics 295, 230-234.

Alessio H \& Goldfarb A (1988) Lipid peroxidation and scavenger enzymes during exercise: adaptive response to training. Journal of Applied Physiology 64, 1333-1336.

Armstrong R \& Phelps R (1984) Muscle fiber type composition of the rat hindlimb. American Journal of Anatomy 171, 259-272.

Barclay JK \& Hansel M (1991) Free radicals may contribute to oxidative skeletal muscle fatigue. Canadian Journal of Physiology and Pharmacology 69, 279-284.

Beyer RE, Morales-Corral P, Ramp B, Kreitman KR, Falzon MJ, Rhee SY, Kuhn TW, Stein M, Rosenwasser MJ \& Cartwright KJ (1984) Elevation of tissue coenzyme Q (ubiquinone) and cytochrome $\mathrm{C}$ concentrations by endurance exercise in the rat. Archives of Biochemistry and Biophysics 234, 323-329.

Borzone G, Zhao B, Merola AJ, Berliner L \& Clanton TL (1994) Detection of free radicals by electron spin resonance in rat diaphragm after resistive loading. Journal of Applied Physiology 77, 812-818

Bowles DK, Torgan CE, Ebner S, Kehrer JP, Ivy JL \& Staines JW (1991) Effects of acute, submaximal exercise on skeletal muscle vitamin E. Free Radical Research Communications 14, 139-143.

Burton GW \& Ingold KU (1989) Vitamin E as an in vitro and in vivo antioxidant. Annals of the New York Academy of Sciences 570, 7-22.

Burton GW \& Traber MG (1990) Vitamin E: antioxidant activity, biokinetics, and bioavailability. Annual Review of Nutrition 10, 357-382.

Criswell D, Powers S, Dodd S, Lawler J, Edwards W, Renshler K \& Grinton S (1993) High intensity training-induced changes in skeletal muscle antioxidant activity. Medicine and Science in Sports and Exercise 25, 1135-1140.

Davies KJ, Quintanilha AT, Brooks GA \& Packer L (1982) Free radicals and tissue damage produced by exercise. Biochemical and Biophysical Research Communications 107, 1198-1205.

Gohil K, Packer L, deLumen B, Brooks GA \& Terblanche SE (1986) Vitamin E deficiency and vitamin C supplements: exercise and mitochondrial oxidation. Journal of Applied Physiology 60, 1986-1991.

Gohil K, Rothfuss L, Lang J \& Packer L (1987) Effect of exercise training on tissue vitamin E and ubiquinone content. Journal of Applied Physiology 63, 1638-1641.

Grisham M \& McCord J (1986) Physiology of Oxygen Radicals. Baltimore, MD: Williams and Wilkins.

Halliwell B \& Gutteridge JM (editors) (1989) Iron toxicity and oxygen radicals. In Free Radicals in Biology and Medicine, 2nd ed., pp. 86-123. Oxford: Clarendon Press.

Hammeren J, Powers S, Lawler J, Criswell D, Martin D, Lowenthal D \& Pollock M (1992) Exercise training-induced alterations in skeletal muscle oxidative and antioxidant enzyme activity in senescent rats. International Journal of Sports Medicine 13, 412-416.

Hellsten Y, Apple F \& Sjodin B (1996) Effect of sprint cycle training on activities of antioxidant enzymes in human skeletal muscle. Journal of Applied Physiology 81, 1484-1487.

Higuchi M, Cartier LJ, Chen M \& Holloszy JO (1985) Superoxide dismutase and catalase in skeletal muscle: adaptive response to exercise. Journal of Gerontology 40, 281-286. 
Jackson M (1998) Free radical mechanisms in exercise-related muscle damage. In Oxidative Stress in Skeletal Muscle, pp. 75-86 [AZ Reznick, L Packer, CK Sen, JO Holloszy and MJ Jackson, editors]. Basel: Birkhauser Verlag.

Jackson MJ, Edwards RH \& Symons MC (1985) Electron spin resonance studies of intact mammalian skeletal muscle. Biochimica et Biophysica Acta 847, 185-190.

Janero DR (1991) Therapeutic potential of vitamin E against myocardial ischemic-reperfusion injury. Free Radical Biology and Medicine 10, 315-324.

Jenkins R (1983) The role of superoxide dismutase and catalase in muscle fatigue. In Biochemistry of Exercise, vol.13, pp. 467-471 $[\mathrm{H}$ Knuttgen, editor]. Champaign, IL: Human Kinetics Publishers.

Ji LL (1995a) Exercise and oxidative stress: role of the cellular antioxidant systems. Exercise and Sport Science Reviews 23, $135-166$.

Ji LL (1995b) Oxidative stress during exercise: implication of antioxidant nutrients. Free Radical Biology and Medicine 18, 1079-1086.

Ji LL, Fu R \& Mitchell E (1992) Glutathione and antioxidant enzymes in skeletal muscle: effects of fiber type and exercise intensity. Journal of Applied Physiology 73, 1854-1859.

Ji LL, Stratman F \& Lardy H (1988) Antioxidant enzyme systems in rat liver and skeletal muscle. Archives of Biochemistry and Biophysics 263, 150-160.

Kagan VE, Bakalova RA, Serbinova EE \& Stoytchev TS (1990) Fluorescence measurements of incorporation and hydrolysis of tocopherol and tocopheryl esters in biomembranes. Methods in Enzymology 186, 355-367.

Kagan VE, Shvedova A, Serbinova E, Khan S, Swanson C, Powell R \& Packer L (1992) Dihydrolipoic acid-a universal antioxidant both in the membrane and in the aqueous phase. Reduction of peroxyl, ascorbyl and chromanoxyl radicals. Biochemistry and Pharmacology 44, 1637-1649.

Karlsson J, Lin L \& Sylven C (1996) Muscle ubiquinone in healthy physically active males. Molecular and Cellular Biochemistry 156, 169-172.

Krinsky NI \& Deneke SM (1982) Interaction of oxygen and oxy-radicals with carotenoids. Journal of the National Cancer Institute 69, 205-210.

Laughlin MH, Simpson T, Sexton WL, Brown OR, Smith JK \& Korthuis KJ (1990) Skeletal muscle oxidative capacity, antioxidant enzymes, and exercise training. Journal of Applied Physiology 68, 337-343.

Lawler J, Powers S \& Criswell D (1993) Inducibility of NADPspecific isocitrate dehydrogenase with endurance training in skeletal muscle. Acta Physiologica Scandinavica 149, 177-181.

Leeuwenburg C, Fiebig R, Chandwaney R \& Ji LL (1994) Aging and exercise training in skeletal muscle: responses of glutathione and antioxidant enzyme systems. American Journal of Physiology 267, R439-R445.

Leeuwenburgh C, Hollander J, Fiebig R, Leichtweis S, Griffith M \& Li JJ (1997) Adaptations of glutathione antioxidant system to endurance training are tissue and muscle fiber specific. American Journal of Physiology 272, R363-R369.

Marin E, Kretzschmar M, Arokoski J, Hanninen O \& Klinger W (1993) Enzymes of glutathione synthesis in dog skeletal muscles and their response to training. Acta Physiologica Scandinavica 47, 369-373.

Meister A \& Anderson ME (1983) Glutathione. Annual Reviews of Biochemistry 52, 711-760.

Mellors A \& Tappel AL (1966) The inhibition of mitochondrial peroxidation by ubiquinone and ubiquinol. Journal of Biological Chemistry 241, 4353-4356.

Meydani M, Evans W, Handelman G, Biddle L, Fielding RA, Meydani SN, Burrill J, Fiatarone MA, Blumberg JB \& Cannon
JG (1993) Protective effect of vitamin E on exercise-induced oxidative damage in young and older adults. American Journal of Physiology 264, R992-R998.

Nashawati E, Dimarco A \& Supinski G (1993) Effects produced by infusion of a free radical-generating solution into the diaphragm. American Review of Respiratory Disease 147, 60-65.

Novelli GP, Bracciotti G \& Falsini S (1990) Spin-trappers and vitamin $\mathrm{E}$ prolong endurance to muscle fatigue in mice. Free Radical Biology and Medicine 8, 9-13.

Oberly L, St Clair D, Autor A \& Oberly T (1987) Increase in manganese superoxide dismutase activity in the mouse heart after X-irradiation. Archives of Biochemistry and Biophysics 254, 69-80.

Oh-ishi S, Kizaki T, Nagasawa J, Izawa T, Komabayashi T, Nagata N, Suzuki K, Taniguchi N \& Ohno H (1997a) Effects of endurance training on superoxide dismutase activity, content and mRNA expression in rat muscle. Clinical and Experimental Pharmacology and Physiology 5, 326-332.

Oh-ishi S, Kizaki T, Ookawara T, Sakurai T, Izawa T, Nagata N \& Ohno H (1997b) Endurance training improves the resistance of rat diaphragm to exercise-induced oxidative stress. American Journal of Respiratory and Critical Care Medicine 156, $1579-1585$.

Ohno H, Suzuki K, Ffujii J, Yamashita H, Kizaki T, Oh-ishi S \& Taniguchi N (1994) Exercise and Oxygen Toxicity. Amsterdam: Elsevier Publishers.

O'Neill CA, Stebbins CL, Bonigut S, Halliwell B \& Longhurst JC (1996) Production of hydroxyl radicals in contracting skeletal muscle of cats. Journal of Applied Physiology 81, 1197-1206.

Oyanuagui Y (1984) Reevaluation of assay methods and establishment of kit for superoxide dismutase activity. Analytical Biochemistry 142, 290-296.

Packer L (1991) Protective role of vitamin E in biological systems. American Journal of Clinical Nutrition 53, 1050S-1055S.

Packer L (1994) Antioxidant properties of lipoic acid and its therapeutic effects in prevention of diabetes complications and cataracts. Annals of the New York Academy of Sciences 738, 257264.

Packer L, Almada A \& Rothfuss L (1989) Modulation of tissue vitamin E levels by physical exercise. Annals of the New York Academy of Sciences 570, 311-321.

Packer JE, Slater TF \& Willson RL (1979) Direct observation of a free radical interaction between vitamin $\mathrm{E}$ and vitamin C. Nature 278, 737-738.

Pette D \& Dusterhoft S (1992) Altered gene expression in fasttwitch induced by chronic low-frequency stimulation. American Journal of Physiology 262, R333-R338.

Powers S, Criswell D, Lawler J, Ji L, Martin D, Herb R \& Dudley G (1994a) Influence of exercise and fiber type on antioxidant enzyme activity in rat skeletal muscle. American Journal of Physiology 266, R375-R380.

Powers S, Criswell D, Lawler J, Martin D, Ji L, Herb R \& Dudley G (1994b) Regional training-induced alterations in diaphragmatic oxidative and antioxidant enzymes. Respiration Physiology 95, 227-237.

Powers S, Ji C \& Leeuwenburgh C (1999) Exercise traininginduced alterations in skeletal muscle antioxidant capacity: a brief review. Medicine and Science in Sports and Exercise (In the Press).

Powers S, Lawler J, Criswell D, Lieu F-K \& Martin D (1992) Aging and respiratory muscle metabolic plasticity: effects of endurance training. Journal of Applied Physiology 72, 1068-1073.

Powers S \& Sen C (1999) Physiological antioxidants and exercise training. In Exercise and Oxygen Toxicity [C Sen and L Packer, editors]. Amsterdam: Elsevier (In the Press).

Reid M, Haack K, Franchek K, Valberg PA, Kobzik L \& West MS (1992a) Reactive oxygen in skeletal muscle: I. Intracellular 
oxidant kinetics and fatigue in vitro. Journal of Applied Physiology 73, 1797-1804.

Reid M, Shoji T, Moody M \& Entman ML (1992b) Reactive oxygen in skeletal muscle. II. Extracellular release of free radicals. Journal of Applied Physiology 73, 1805-1809.

Reid MB, Stokic DS, Koch SM, Khawli FA \& Leis AA (1994) $\mathrm{N}$-acetylcysteine inhibits muscle fatigue in humans. Journal of Clinical Investigation 94, 2468-2474.

Salminen A \& Vihko V (1983) Endurance training reduces the susceptibility of mouse skeletal muscle to lipid peroxidation in vitro. Acta Physiologica Scandinavica 117, 109-113.

Sen CK, Marin E, Kretzschmar M \& Hanninen O (1992) Skeletal muscle and liver glutathione homeostasis in response to training, exercise, and immobilization. Journal of Applied Physiology 73, $1265-1272$.

Shindoh C, Dimarco A, Thomas A, Manubay P \& Supinski G (1990) Effect of N-acetylcysteine on diaphragm fatigue. Journal of Applied Physiology 68, 2107-2113.

Starnes J, Cantu G, Farrar R \& Kehrer JP (1989) Skeletal muscle lipid peroxidation in exercised and food-restricted rats during aging. Journal of Applied Physiology 67, 69-75.
Tiidus P \& Houston M (1993) Vitamin E status does not affect the responses to exercise training and acute exercise in female rats. Journal of Nutrition 123, 834-840.

Vandenburgh H (1992) Mechanical forces and their second messengers in stimulating cell growth in vitro. American Journal of Physiology 262, R350-R355.

Venditti P \& Di Meo S (1996) Antioxidants, tissue damage, and endurance in trained and untrained young male rats. Archives of Biochemistry and Biophysics 331, 63-68.

Venditti P \& Di Meo S (1997) Effect of training on antioxidant capacity, tissue damage, and endurance of adult male rats. International Journal of Sports Medicine 18, 497-502.

Vina J, Sastre J, Asensi M \& Packer L (1995) Assay of blood glutathione oxidation during physical exercise. Methods in Enzymology 251, 237-243.

Vincent H, Powers S, Demirel H, Coombes J \& Naito H (1999) Exercise training protects against contraction-induced lipid peroxidation in the diaphragm. European Journal of Applied Physiology 79, 268-273.

Yu B (1994) Cellular defenses against damage from reactive oxygen species. Physiological Reviews 74, 139-162. 